Original Research Article

\title{
Adverse drug reaction reporting in a tertiary care teaching hospital in eastern India: a retrospective study
}

\author{
Debasish Misra*, Manika Bose, Sansita Parida, Smita Das, \\ Swati Mishra, Sudhansu Sekhar Mishra
}

Department of Pharmacology, Institute of Medical Science and Sum Hospital, Bhubaneswar, Odisha, India

Received: 17 August 2019

Revised: 13 September 2019

Accepted: 16 September 2019

*Correspondence to:

Dr. Debasish Misra,

Email: debasishmisra@soa.ac.in

Copyright: (C) the author(s), publisher and licensee Medip Academy. This is an openaccess article distributed under the terms of the Creative Commons Attribution NonCommercial License, which permits unrestricted noncommercial use, distribution, and reproduction in any medium, provided the original work is properly cited.

\begin{abstract}
Background: Adverse drug reactions (ADRs) are one of the prime causes of morbidity and mortality, increase in hospital stay and socioeconomic burden on the patients. Periodic monitoring aids in formulating methods for safe usage of medicines in hospitals. This study was undertaken to study the patterns, assessment of causality, severity, preventability, body systems affected from ADRs received by the Pharmacovigilance cell, Department of Pharmacology between April 2018 to June 2019.

Methods: The present study is an observational, retrospective, noninterventional analysis of voluntarily reported ADRs. Demography of patients, causative drugs, reactions, outcome, and severity are recorded. Data were analysed and expressed in numbers, percentages.

Results: A total of 180 ADRs were spontaneously reported. Dermatology $(42.8 \%)$, psychiatry $(23.9 \%)$ and general medicine $(18.3 \%)$ are the major departments reporting ADRs in our hospital. 60.6\% reports were in males. The body system with maximum reactions is dermatological $(51.1 \%)$. Drug class most commonly affected is anti-microbials $(36.1 \%)$. Paracetamol $(8.9 \%)$ is the most common drug with reactions. Causality assessment stated that $41.7 \%$ ADRs are probable and $58.3 \%$ were possible. Severity assessment showed $86.7 \%$ as mild and $13.3 \%$ as moderate. Preventability assessment stated that 93.3\% ADRs not preventable, 5.6\% probably preventable and $1.1 \%$ definitely preventable.

Conclusions: The study provides a valuable insight with regards to the pattern of ADRs in our hospital. This will be useful in initiating a reporting culture, increase awareness, reducing under-reporting of ADR in our set up.
\end{abstract}

Keywords: ADRs, Causality, Preventability, Retrospective study, Severity

\section{INTRODUCTION}

Adverse drug reactions (ADRs) are one of the prime causes of morbidity and mortality globally, associated with increase in hospital stay and marked socioeconomic burden on patients in particular and to the healthcare system at large. ${ }^{1}$ It is estimated that $2.85 \%$ of hospitalization is due to adverse drug reactions, and that occurred during hospitalization was $6.34 \% .^{2}$ Children, elderly, females, polypharmacy and patients with hepatic and renal impairment are some of the major factors responsible for these reactions. ${ }^{3}$
WHO defines ADR as "any unintended and noxious response to a drug which occurs at doses normally used in human beings for the prophylaxis, diagnosis or therapy of a disease, or for modification of physiological functions". 4 There are six categories of ADRs: type A is related to dose and most common, type $\mathrm{B}$ is not related to dose, type $\mathrm{C}$ is related to dose and time, type $\mathrm{D}$ is related to time, type $\mathrm{E}$ is end of use, and type $\mathrm{F}$ is failure of therapy. 5

Voluntary reporting of adverse drug reactions by the health care professionals is the mainstay in generating 
data for onward submission to regulatory authorities. Clinicians are best suited to report ADRs, however, due to lack of interest, attitude and time, many of these reactions were never reported. Underreporting is a major problem in our country. Hence, there is a need to increase health care professional's awareness on prevention, identification, and reporting of reactions.

Periodic monitoring of reactions in a hospital guides us in mapping the different patterns of reactions. This helps us in formulating methods to inculcate ways for safe usage of medicines in hospitals, and individualizing patient therapy. ${ }^{6}$

Hence, the study was undertaken to analyse the incidence, patterns, along with assessment of causality, severity, preventability, outcome, drugs causing and body systems affected in various adverse reactions reported.

\section{METHODS}

\section{Study design}

This study is an observational, retrospective, noninterventional analysis of voluntarily reported ADRs forms received at Pharmacovigilance cell, Department of Pharmacology, IMS and SUM Hospital, Bhubaneswar between April 2018 to June 2019. The study was duly approved by the Institutional Ethics Committee. For additional information, on the reported ADR forms, concerned clinician who reported were contacted.

\section{Inclusion criteria}

Patients of either sex of any age who developed an ADR, patients from the outpatient or inpatient department (wards and ICU) having any adverse reaction (s).

\section{Exclusion criteria}

Patients who developed an ADR due to poisoning of drugs (accidental or intentional), blood or blood products and vaccines and ADRs due to alternate systems of medicines like homeopathy, ayurvedic, unani, etc., were excluded from the study.

Demography of patient, causative drug, reaction, outcome, and severity are recorded in the Central Drug Standard Control Organization approved ADR reporting form. Confidentiality of data was maintained. Analysis and evaluation of the reported data done on several parameters viz;

Patient parameters: Age, gender.

\section{Adverse drug reaction parameters}

Categorized depending on the body system affected, departments from where the forms were generated, and whether from OPD or IPD.

\section{Medication parameters}

The medication causing the reactions categorized to different classes of drugs and their routes of administration.

\section{Assessment of causality}

Done by Naranjo's adverse drug reaction probability scale. These reactions are classified into definite, probable, possible or doubtful. ${ }^{7}$

\section{Assessment of severity}

Reactions are classified into mild, moderate or severe based on modified Hartwig and Siegel scale. ${ }^{8}$

\section{Assessment of preventability}

Reactions categorized into definitely preventable, probably preventable, and not preventable based on the modified Schumock and Thornton criteria. ${ }^{9}$

\section{Assessment of outcome}

Outcome reported as recovered, recovering, and failed to recover, unknown or fatal.

\section{Assessment of predictability}

Assessed using the classification of Rawlins and Thompson: type A (augmentation of the pharmacological actions of a drug, dose dependent and predictable) or type $\mathrm{B}$ (idiosyncratic). ${ }^{10}$

\section{Statistical analysis}

Data obtained were expressed in numbers, percentages, wherever appropriate. Data were subdivided into age, gender, drugs causing, body systems involved. P-value was calculated. $\mathrm{P}<0.05$ was considered statistically significant.

\section{RESULTS}

A total of 180 ADRs were reported spontaneously in the present study. 70996 patients were admitted and 1248622 visited outpatient's department in the duration of the study. 180 adverse drug reactions reported from a total of 1319618 patients. $0.01 \%$ is the incidence of adverse drug reactions from our hospital. $65 \%$ of the reactions were reported from outpatient's department and 35\% from inpatients department.

Dermatology $(42.8 \%)$, psychiatry $(23.9 \%)$ and general medicine $(18.3 \%)$ are the major three departments reporting ADRs in our hospital. Other departments are Critical care unit (ICU) $(7.2 \%)$, pulmonary medicine $(4.4 \%)$, paediatrics $(2.2 \%)$, cardiothoracic surgery and 
general surgery $(0.6 \%)$. Maximum reactions reported are from per oral administration (80\%) and parenteral $(20 \%)$. No other routes of administration contributed any adverse reaction in our set up.

Analysing the patient parameters, we found more reactions reported are in males $(60.6 \%)$ and adults between $31-45$ years $(42.8 \%)$, succeeded by $16-30$ years $(42.3 \%)$ and $46-60$ years $(38.8 \%)$. The distribution of demographic details (age group and gender) and the number of ADRs summarized (Table 1).

Table 1: Distribution of demographic details and ADRs.

\begin{tabular}{|llll|}
\hline $\begin{array}{l}\text { Age group } \\
\text { (years) }\end{array}$ & No. of ADRs & Male & Female \\
\hline $\mathbf{0 - 1 5}$ & $11(6.1)$ & $\mathrm{N}(\%)$ & $\mathrm{N}(\%)$ \\
\hline $\mathbf{1 6 - 3 0}$ & $46(25.6)$ & $30(16.7)$ & $3(1.7)$ \\
\hline $\mathbf{3 1 - 4 5}$ & $50(27.8)$ & $27(15.0)$ & $23(12.8)$ \\
\hline $\mathbf{4 6 - 6 0}$ & $44(24.4)$ & $26(14.4)$ & $18(10.0)$ \\
\hline $\mathbf{6 1 - 7 5}$ & $28(15.6)$ & $17(9.4)$ & $11(6.1)$ \\
\hline $\mathbf{7 6}$ & $1(0.5)$ & $1(0.5)$ & 0 \\
\hline
\end{tabular}

The gender wise distribution of ADRs as per body system involvement enumerated. There is a significant difference between males and females for dermatological system. $51.1 \%$ of ADRs involves dermatological system (Table 2).
Table 2: Gender wise distribution of ADRs as per body system involvement.

\begin{tabular}{|llll|}
\hline Body system & Male & Female & P-value \\
\hline Dermatological & $\mathbf{N}(\boldsymbol{\%})$ & $\mathbf{N}(\boldsymbol{\%})$ & \\
\hline Neuropsychiatry & $11(6.1)$ & $33(18.3)$ & $0.007^{*}$ \\
\hline Body as a whole & $13(7.2)$ & $12(6.7)$ & 0.655 \\
\hline GI system & $18(10.0)$ & $12(6.7)$ & 0.841 \\
\hline Genitourinary & $3(1.7)$ & $2(1.1)$ & 0.655 \\
\hline Eye & $2(1.1)$ & $1(0.5)$ & 0.569 \\
\hline
\end{tabular}

*Significant.

The body system most commonly affected is dermatological $(51.1 \%)$ and the most frequently reported reactions was fixed drug eruptions $(23.3 \%)$ followed by rash $(11.1 \%)$, diarrhoea $(6.7 \%)$ and redness/itching (4.4\%) (Table 3).

The drug class most commonly affected are antimicrobials $(36.1 \%)$ followed by antipsychotics $(15.6 \%)$, analgesics or anti-inflammatory $(8.9 \%)$. In antimicrobials and antipsychotics, reaction was most frequently attributed to ornidazole $(7.2 \%)$ and risperidone (6.1\%) respectively. The drug category and causative drug which is frequently associated with adverse reactions enumerated (Table 4).

Table 3: Body systems affected and frequent adverse reactions reported (>4 ADRs).

\begin{tabular}{|c|c|c|c|}
\hline \multirow{2}{*}{$\begin{array}{l}\text { Body system } \\
\text { involvement }\end{array}$} & \multirow{2}{*}{$\begin{array}{l}\text { Adverse drug reactions } \\
\mathbf{N}(\%)\end{array}$} & \multirow{2}{*}{ Reactions } & \multirow{2}{*}{$\begin{array}{l}\text { ADRs } \\
\text { N }(\%)\end{array}$} \\
\hline & & & \\
\hline \multirow{6}{*}{ Dermatological } & \multirow{6}{*}{$92(51.1)$} & FDE $^{\#}$ & $42(23.3)$ \\
\hline & & Rash & $20(11.1)$ \\
\hline & & SDRIFE* & $05(2.8)$ \\
\hline & & Urticaria & $05(2.8)$ \\
\hline & & Redness or itching & $08(4.4)$ \\
\hline & & Black pigmentation & $04(2.2)$ \\
\hline Neuropsychiatry & $20(11.1)$ & Tremor & $07(3.9)$ \\
\hline \multirow{3}{*}{ Body as a whole } & \multirow{3}{*}{$25(13.9)$} & Pedal oedema & $07(3.9)$ \\
\hline & & DRESS $^{ \pm}$ & $06(3.3)$ \\
\hline & & Weight gain & $06(3.3)$ \\
\hline \multirow{3}{*}{ GI system } & \multirow{3}{*}{$30(16.7)$} & Diarrhoea & $12(6.7)$ \\
\hline & & Hepatitis & $06(3.3)$ \\
\hline & & Vomiting & $05(2.8)$ \\
\hline Genitourinary system & $05(2.8)$ & $\mathrm{AKI}^{\square}$ & $04(2.2)$ \\
\hline
\end{tabular}

${ }^{\#}$ FDE: Fixed drug eruptions; *SDRIFE: Symmetrical and drug-related intertriginous and flexural exanthema; ${ }^{ \pm}$DRESS: Drug reaction with eosinophilia and systemic symptoms and ${ }^{\square}$ AKI: Acute kidney injury.

However, paracetamol $(8.9 \%)$ and diclofenac $(7.8 \%)$ are the two most commonly reported drugs with ADRs. FDE is the most common reaction observed with paracetamol, diclofenac and ornidazole. The drugs which are frequently involved with adverse reactions depicted (Table 5).
In the final outcomes of the reported ADRs, majority $(82.2 \%)$ have recovered, $16.7 \%$ are recovering and $1.1 \%$ unknown. Assessment of causality by Naranjo revealed $75(41.7 \%)$ were probable and 105 (58.3) are possible adverse reactions. There were no ADRs which were definite or doubtful. Severity assessment by Hartwig and Siegel scale showed $156(86.7 \%)$ as mild and $24(13.3 \%)$ as moderate. There were no severe cases. 
Table 4: Drug category and causative drugs frequently associated with ADRs (>4 ADRs).

\begin{tabular}{|c|c|c|c|}
\hline \multirow{2}{*}{ Drug category } & ADRs & \multirow{2}{*}{ Drug } & ADRs \\
\hline & $\mathbf{N}(\%)$ & & $\mathbf{N}(\%)$ \\
\hline \multirow{6}{*}{ Anti-microbials } & \multirow{6}{*}{$65(36.1)$} & Ornidazole & $13(7.2)$ \\
\hline & & Amoxycillin or clavulanic acid & $07(3.9)$ \\
\hline & & Ciprofloxacin & $05(2.8)$ \\
\hline & & Vancomycin & $05(2.8)$ \\
\hline & & Ceftriaxone & $05(2.8)$ \\
\hline & & Tinidazole & $04(2.2)$ \\
\hline Antiepileptics & $09(5.0)$ & Sodium valproate & $04(2.2)$ \\
\hline Antimycobacterial & $10(5.5)$ & 4 drug ATT $^{*}$ & $10(5.5)$ \\
\hline \multirow{3}{*}{ Antipsychotic } & \multirow{3}{*}{$28(15.6)$} & Risperidone & $11(6.1)$ \\
\hline & & Olanzapine & $09(5.0)$ \\
\hline & & Haloperidol & $04(2.2)$ \\
\hline Analgesic & $16(8.9)$ & Paracetamol & $16(8.9)$ \\
\hline Anti-inflammatory & $16(8.9)$ & Diclofenac & $14(7.8)$ \\
\hline Antifungal & $09(5.0)$ & Itraconazole & $04(2.2)$ \\
\hline
\end{tabular}

*ATT: Antitubercular therapy.

Table 5: Drugs frequently involved with adverse reactions (>4 ADRs).

\begin{tabular}{|ll|l|}
\hline Drugs & Reaction details & Total (n=180) \\
\hline Paracetamol & Maculopapular eruptions (3), black pigmentation (2), rash (4), & 16 (8.9) \\
\hline Diclofenac & FDE (6), DRESS (1) & $14(7.8)$ \\
\hline Ornidazole & Rash (2), fluid filled bullae (1), urticaria (3), FDE (8) & $13(7.2)$ \\
\hline & Hyperpigmented patch (4), rash (1), FDE (8) & $11(6.1)$ \\
\hline Risperidone & Weight gain (2), sedation (1), tremor (2), slow movement (1), & \\
\hline urticaria (1), restless leg syndrome (2), decreased libido (1), \\
pedal oedema (1) & Hepatitis (7), FDE (1), DRESS (1), blurred vision (1) & $10(5.5)$ \\
\hline Olanzapine & Pedal oedema (5), sedation (2), weight gain (2) & $9(5.0)$ \\
\hline Amoxycillin+clavulanic acid & Rash (3), FDE (1), itching (1), DRESS (1), epigastric pain (1) & $7(3.9)$ \\
\hline Ciprofloxacin & Maculopapular eruptions (2), FDE (3) & $5(2.8)$ \\
\hline Ceftriaxone & Itching (5) & $5(2.8)$ \\
\hline Vancomycin & Itching (2), vomiting (1), rash (1), AKI (1) & $5(2.8)$ \\
\hline Haloperidol & Restless leg syndrome (1), tremor (2), rigidity (1) & $4(2.2)$ \\
\hline Itraconazole & SDRIFE (4) & $4(2.2)$ \\
\hline Tinidazole & FDE (2), maculopapular rash (2) & $4(2.2)$ \\
\hline Sodium valproate & Pedal oedema (1), alopecia (1), weight gain (1), tremor (1) & $4(2.2)$ \\
\hline
\end{tabular}

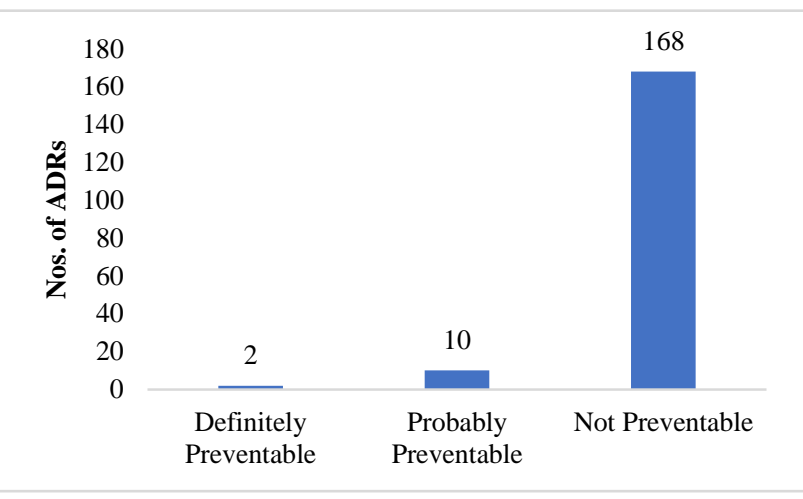

Figure 1: Preventability assessment by modified Schumock and Thornton scale. ${ }^{9}$
Assessment of preventability by modified Schumock and Thornton scale (Figure 1).

Assessment of predictability by Rawlins and Thompson indicated that $76.1 \%$ were type A and $23.9 \%$ were type B ADRs.

\section{DISCUSSION}

ADRs represent an important clinical issue and have a deleterious effect not only on the well-being of the patient but also on the overall health care system. ADRs contribute significantly to patient's morbidity and mortality and poses significant public health challenge and concern. ${ }^{11,12}$ 
A continuing adverse reaction preventive program in a hospital can guide us on the safety of drug therapies, measure the incidence rates, educate and increase awareness amongst healthcare professionals on detection and reporting of adverse reactions. ${ }^{13}$

The overall incidence of ADRs reported in our study (both inpatient and outpatient) was $0.01 \%$, as compared to $0.15 \%$ in the study by Jose, $0.044 \%$ in the study by Singh et al, $0.67 \%$ in the study by Pathak et al and $9.8 \%$ in the study by Arulmani et al. ${ }^{14-17}$ The low incidence of ADR reporting in our study could be due to many factors such as lack of awareness about reporting, lack of time, etc.

In the study by Singh et al majority of adverse reactions were reported from IPD $(78.45 \%)$ and OPD $(21.55 \%)$, as compared to $35 \%$ and $65 \%$ respectively in our study. ${ }^{15}$

The department reporting maximum ADR are general medicine $(41.9 \%)$, gynaecology $(22.0 \%)$ and skin and VD $(33.22 \%)$, in the study by Jose, Singh et al, and Pathak et al respectively, as compared to skin and VD $(42.8 \%)$ in our study. ${ }^{15-17}$

Oncology (26.0\%) and neurology (12.5\%) by Jose, oncology $(21.0 \%)$ and general medicine $(15.0 \%)$ by Singh et al, oncology (18.84\%), and general medicine (14.04\%), by Pathak et al were the other major ADR reporting departments as compared to psychiatry $(23.9 \%)$ and general medicine $(18.3 \%)$ in our study. ${ }^{14-16}$ There were no reported ADRs from oncology, neurology and gynaecology department in the study period.

In the study by Singh et al per oral, parenteral and topical route of administration contributed $41.81 \%, 56.89 \%$ and $1.29 \%$ of reactions. ${ }^{15}$ Study by Pathak et al intravenous route and per oral contributed $55.14 \%$ an $38.36 \%$ of reactions respectively, as compared to $80 \%$ and $20 \%$ by per oral and parenteral route respectively in our study. ${ }^{16}$

More ADR were reported from males $(57.6 \%, 56.5 \%$, $56.8 \%, 61.7 \%$ ) from the study by Jose, Pathak et al, Bhattacharjee et al and Gupta et al, respectively, which was similar to our study $(60.6 \%) .^{14,16,18,19}$ Maximum number of ADRs were reported in the age group of 46-60 years $(31.9 \%)$ and $16-30$ years $(33.9 \%)$ in the study by Jose, and Pathak et al respectively. ${ }^{14,16}$ In our study, the age group of 31-45 years reported the maximum number of adverse reactions (42.8\%). In the ADR variations based on gender, it was observed that there is a significant difference between males and females for dermatological system.

The body system frequently affected is dermatological which is $23.5 \%, 41 \%, 34.1 \%$ and $68.75 \%$ in the study by Jose, Singh et al, Arulmani et al, and Patidar et al respectively, and similar $(51.1 \%)$ to our study. ${ }^{14,15,17,20}$ FDEs $(23.3 \%)$ was the most common dermatological reaction in our study, which was similar to the study by
Sharma. ${ }^{21}$ FDEs was the most common reaction involved for paracetamol, diclofenac, ciprofloxacin and tinidazole.

The most common drug class causing the ADRs in our study are antimicrobials $(36.1 \%)$. This result is consistent with the study carried out by Arulmani, Sharma, Roy and Jayanthi. ${ }^{17,21-23}$

The other drug classes contributing to ADR in our set up were antipsychotic (15.6\%), analgesics $(8.9 \%)$ and antiinflammatory $(8.9 \%)$. The most common drugs responsible for these reactions are paracetamol $(8.9 \%)$, diclofenac $(7.8 \%)$, ornidazole $(7.2 \%)$, and risperidone (6.1\%).

Our study revealed that $82.2 \%$ of the study population recovered from the ADRs, which was similar to the study of Jose, Pathak et al and Arulmani et al. ${ }^{14-17}$

In our study, causality assessment by Naranjo scale showed that $41.7 \%$ were probable and $58.3 \%$ were possible. Assessment of severity by Hartwig and Siegel scale indicated $86.7 \%$ as mild and $13.3 \%$ as moderate. No severe adverse reactions have been encountered in our centre during the study period. Assessment of preventability by modified Schumock and Thornton criteria revealed that $93.3 \%$ of ADRs are not preventable, $5.6 \%$ were probably preventable and only $1.1 \%$ definitely preventable.

Predictability assessment by Rawlins and Thompson indicated that $76.1 \%$ were predictable (type A) and $23.9 \%$ were not predictable (type B). This is consistent with the study done by Jose, Bhattacharjee and Jayanthi. $^{14,18,23}$

\section{CONCLUSION}

ADRs are one of the most important causes of morbidity, mortality and prolonged hospitalization in patients. Reporting of adverse reactions to medications is useful for identification and reducing preventable reactions. This further allows the physician to manage the conditions more efficiently. The study provides valuable insight as regards to the pattern of ADRs in our hospital. The pattern of ADR evaluated on some parameters in our set up was similar to other studies. ${ }^{14-23}$ This study will be useful in initiating a reporting culture, educate and increase awareness amongst health care professionals and to reduce under-reporting in our hospital.

\section{ACKNOWLEDGEMENTS}

The authors would like to thank the health care professionals who reported the ADRs during the period April 2018 to June 2019.

\section{Funding: No funding sources}

Conflict of interest: None declared

Ethical approval: The study was approved by the Institutional Ethics Committee 


\section{REFERENCES}

1. Lazarou J, Pomeranz BH, Corey PN. Incidence of adverse drug reactions in hospitalized patients: A meta-analysis of prospective studies. JAMA. 1998;279:1200-5.

2. Patel TK, Patel PB. Incidence of adverse drug reactions in Indian hospitals. A systematic review of prospective studies. Curr Drug Saf. 2016;11(2):12836.

3. Sultana J, Cutroneo P, Trifiro G. Clinical and economic burden of adverse drug reactions. J Pharmacol Pharmacother. 2013;4(1):73-7.

4. International drug monitoring: the role of national centres. Report of a WHO meeting. World Health Organ Tech Rep Ser. 1972;498:1-25.

5. Edwards IR, Aronson JK. Adverse drug reactions: definitions, diagnosis, and management. Lancet. 2000;356(9237):1255-9.

6. Gallelli L, Ferreri G, Colosimo M, Pirritano D, Flocco MA, Pelaia G, et al. Retrospective analysis of adverse drug reactions to bronchodilators observed in two pulmonary divisions of Catanzaro, Italy. Pharmacol Res. 2003;47(6):493-9.

7. Naranjo CA, Busto U, Sellers EM, Sandor P, Ruiz I, Roberts EA, et al. A method for estimating the probability of adverse drug reactions. Clin Pharmacol Ther. 1981;30:239-45.

8. Hartwig SC, Siegel J, Schneider PJ. Preventability and severity assessment in reporting adverse drug reactions. Am J Hosp Pharm. 1992;49:2229-32.

9. Schumock GT, Thornton JP. Focusing on the preventability of adverse drug reactions. Hosp Pharm. 1992;27:538.

10. Rawlins MD, Thompson JW. Pathogenesis of adverse drug reactions. In: Davies DM, ed. Textbook of adverse drug reactions. 10th ed. Oxford: Oxford University Press; 1977: 27.

11. Ramesh M, Pandit S, Parthsarathi G. Adverse drug reactions in a South Indian hospital-their severity and cost involved. Pharmacoepidemiol Drug Saf. 2003; 12:687-92.

12. Backstorm M, Mjorndal $\mathrm{T}$, Dahlquist $\mathrm{R}$. Underreporting of serious adverse drug reactions. Sweden Pharmacoepidemiol Drug Saf. 2004;13:4837.

13. American Society of Health System Pharmacists. ASHP guidelines on adverse drug reaction monitoring and reporting. Am J Hosp Pharm. 1989;46:336-7.
14. Jose J, Rao PGM. Pattern of adverse drug reactions notified by spontaneous reporting in an Indian tertiary care teaching hospital. Pharmacol Res. 2006;54:226-33.

15. Singh P, Agrawal M, Hishikar R, Joshi U, Maheshwari B, Halwai A. Adverse drug reactions at adverse drug reaction monitoring center in Raipur: analysis of spontaneous reports during 1 year. Indian J Pharmacol. 2017;49:432-7.

16. Pathak AK, Kumar M, Dokania S, Mohan L, Dikshit H. A Retrospective analysis of reporting of adverse drug reactions in a tertiary care teaching hospital: one-year survey. J Clin Diagnos Res. 2016;10(8):1-4.

17. Arulmani R, Rajendran SD, Suresh B. Adverse drug reaction monitoring in a secondary care hospital in South India. Br J Clin Pharmacol. 2007;65(2):210-6.

18. Bhattacharjee P, Das L, Ghosh R, Lalromawii, Das UK. Pattern of adverse drug reactions reported at a tertiary health care teaching hospital of Tripura: a retrospective study. Int J Basic Clin Pharmacol. 2016;5:1293-9.

19. Gupta A, Kaur A, Shukla P, Chhabra H. Adverse drug reactions pattern in a tertiary level teaching hospital: a retrospective study. Indian J Pharm Practice. 2017;10(1):27-31.

20. Patidar D, Rajput MS, Nirmal NP, Savitri W. Implementation and evaluation of adverse drug reaction monitoring system in a tertiary care teaching hospital in Mumbai, India. Interdisciplinar Toxicol. 2013;6(1):41-6.

21. Sharma R, Dogra D, Dogra N. A study of cutaneous adverse drug reactions at a tertiary centre in Jammu, India. Indian Dermatol Online J. 2015;6(3):168-71.

22. Roy K, Divya S, Nadig P, Prakash B. Monitoring and analysis of adverse drug reactions in a private tertiary care teaching hospital. Asian J Pharmaceut Clin Res. 2015;8(2):335-7.

23. Jayanthi CR, Darshini MB. A study to analyze the pattern, causality, severity, predictability, and preventability of adverse drug reactions among patients attending the department of obstetrics and gynecology at a tertiary care hospital. Natl J Physiol Pharm Pharmacol. 2019;9(2):172-7.

Cite this article as: Misra D, Bose M, Parida S, Das S, Mishra S, Mishra SS. Adverse drug reaction reporting in a tertiary care teaching hospital in eastern India: a retrospective study. Int J Basic Clin Pharmacol 2019;8:2322-7. 